\title{
Abgel a way to make light weight maxillary complete denture: An innovative technique
}

\author{
Varsharani Dhakne, ${ }^{1, *}$, Premraj Jadhav², Milind Limaye ${ }^{3}$, Chetan Modgi ${ }^{4}$, Parisha Patil ${ }^{5}$ \\ ${ }^{1,5} \mathrm{MDS},{ }^{2,3}$ Professor, ${ }^{4}$ Reader, ${ }^{1-5}$ Dept of prosthodontics Yogita Dental College \& Hospital Khed muhs nashik \\ *Corresponding Author: \\ Email: varsharani512@gmail.com
}

\begin{abstract}
Maxillary denture in atrophic ridges should be as light weight as possible that will give the retention, stability \& support to maxillary denture. Rehabilitation of such a condition is very difficult due to inadequate support from Hard and soft tissue .This technique describes a novel method for fabrication of a hollow maxillary complete denture. Usage Abgel it's a absorbable gelatin sponge \& this is placed into cavity left by the silicone putty index (Zhermack Zetaplus C Silicone) which gives suitable dimensions between acrylic resin and the denture base resin. Abgel is weightless, sterile \& readily available.
\end{abstract}

Keywords: Atrophic ridges, Hollow denture, Abgel, Gelatine spongue.

\section{Introduction}

Severely worn ridges are one of the great challenges for the dentist to rehabilitate such conditions and also the maxillofacial defects are difficult to restore due to decreased bone support and an increased space between the maxillary ridge and mandibular ridge. This may result in a increased weight of maxillary denture. It will hamper the denture retention stability \& support. $^{1}$ Increased interidge distance creates the leverage forces due to this reason it's important to make light weight maxillary denture. ${ }^{2,3}$ Solid 3 dimensional spacer, dental stone $^{3,7}$ cellophane wrapped asbestos ${ }^{8}$ silicone putty or modeling clay are the materials used for making hollow denture. ${ }^{9}$ Weight reduction of prosthesis may be achieved by making an hollow denture.

This technique describes innovative technique to hollowing maxillary complete denture using Abgel with single flask technique. It is absorbable gelatin sponge with negligible weight, sterile, economical flexible to adapt any shape, during surgery its used to decrease the blood at surgical site as its biocompatible due to this reason it can be remained in denture.

\section{Technique}

1. All the procedure of conventional denture will be followed till try in stage.

2. After that measurements to create the space for spacer was measured by thickness of denture base $(3 \mathrm{~mm}) \&$ the height of teeth from the total height of denture in anterior and from posterior area. This space was calculated \& was further occupied by the Abgel spacer.

3. To prepare index Silicone putty (Zhermack Zetaplus C Silicone) was mixed and made in the form of rope and after that it was cut into dimensions measured from trial denture that were approximately $8 \mathrm{~mm}$ in height and $6 \mathrm{~mm}$ in width. This putty index was used in further steps till trail closure which was shown in Fig. 1.
4. Abgel is nothing but a absorbable gelatine in Sponge form. It is also non-toxic, non-allergenic nonimmunogenic, and non-pyrogenic, gammasterilized which was placed into a space created by the silicone putty index Fig. 2, 3 .

5. Do trial closure using the temporary putty index as seen in Fig. 4.

6. Open the flasks \& retrieve temporary putty index

7. Check the mould space created by putty index for any exposure on buccal and lingual side Fig. 5.

8. Place the abgel spacer into the cavity created by temporary putty index \& final closure of the flasks was achieved as seen in Fig. 6.

9. Acrylization of denture was done in conventional manner.

10. Denture was retrieved in conventional manner following processing as seen in Fig. 7.

11. Abgel gelatine sponge which was used for making light weight denture was remained in situ denture after processing as weight of the sponge is negligible as seen in Fig. 8.

12. Finishing and polishing was done of both the dentures \& delivered to the patient as seen in Fig. 9.

13. The patient was recalled after $24 \mathrm{hrs}, 48 \mathrm{hrs}$, 1 weak, 1 month, 3months and after 6 months for retention, stability, aesthetics \& comfort of the patient.

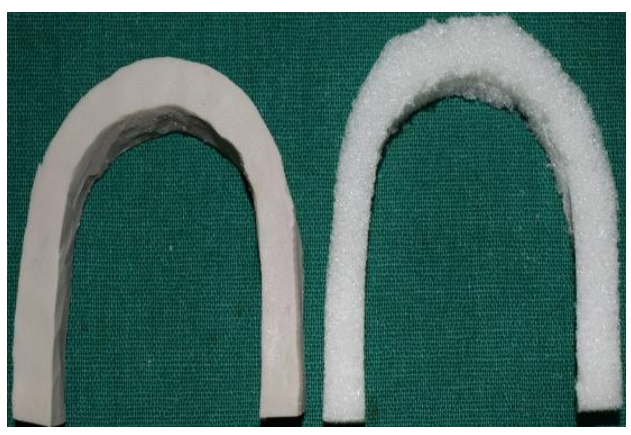

Fig. 1: Silicone putty index And Abgel 


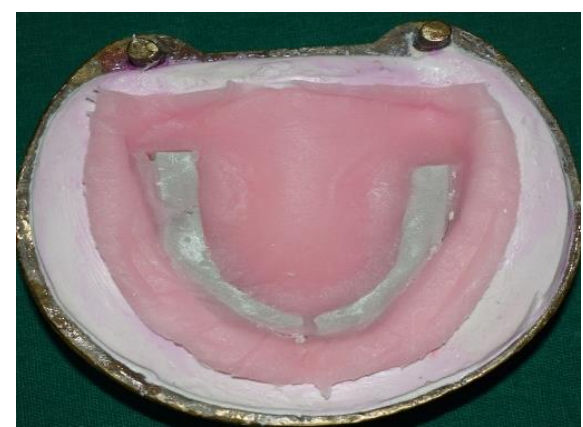

Fig. 2: Trial closure with temporary putty index

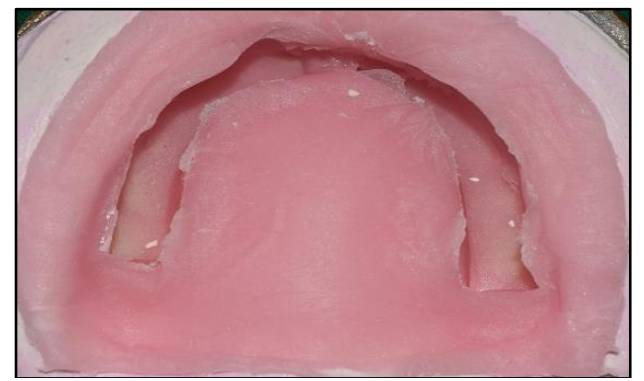

Fig. 3: Assessment of mould space for spacer

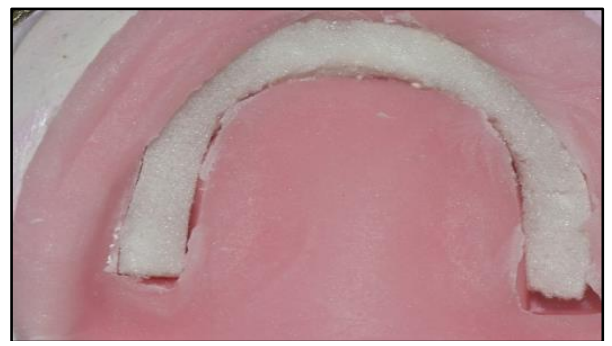

Fig. 4: Placement of abgel in space created by temporary putty spacer

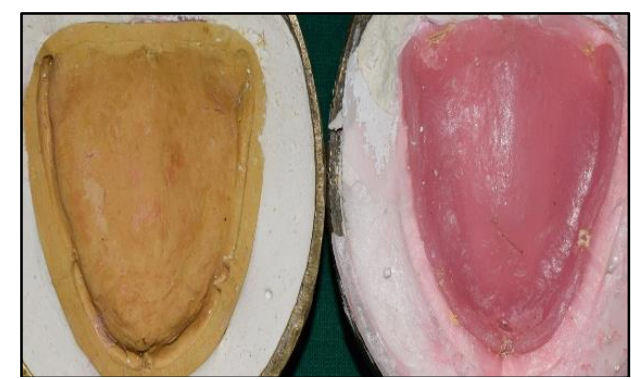

Fig. 5: Retrieval of hollow denture

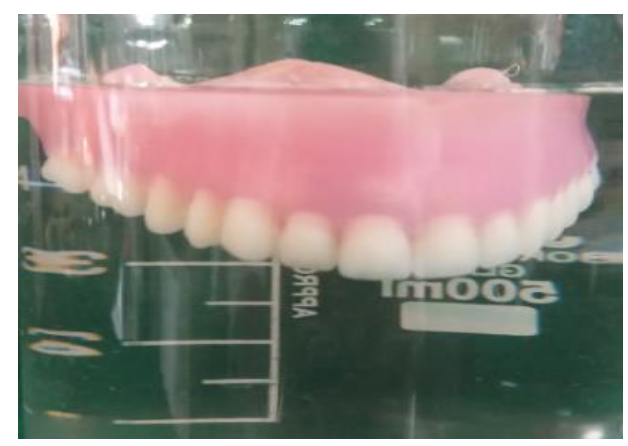

Fig.6: Hollow denture with Abgel inside

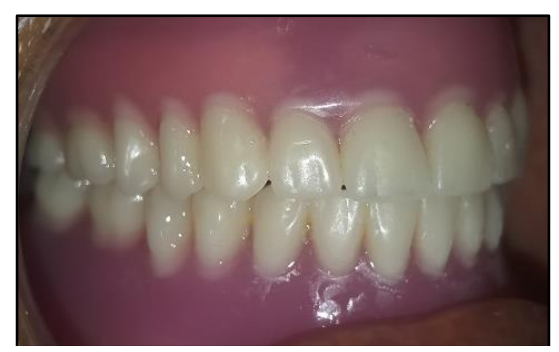

Fig. 7: Finished and polished denture delivered to patient

\section{Discussion}

In previously used methods they were supposed to remove the putty spacer after acrylization but the method used in this method has advantages over previously used methods. ${ }^{5,6,7,9}$ In previous studies small window was made to remove spacer from denture. This window sometimes may leave space after adjustments \& may lead to the leakage but this method has advantage that leaves the abgel spacer into denture. Leakage from window was the problem in previously described technique. ${ }^{2,-10,13,14,16-19}$ Silicone putty (Zhermack Zetaplus C Silicone) was mixed and made in the form of rope and after that it was cut into dimensions measured from trial denture that approximately $8 \mathrm{~mm}$ in height and $6 \mathrm{~mm}$ in width Then the flask lids were closed and the silicone putty placed on the denture base forms an index for hollow space for the abgel gelatine sponge. Ashok Jhanji in (1991) uses silicone putty as the obturating material as opposed to sugar, asbestos or other silicone rubber foams that can be messy dangerous and unstable. This technique can also be used for patients with atrophic maxillae where the hollow denture can significantly reduce the weight of the restoration. ${ }^{17}$ This silicone putty index gives particular depth of resin to prevent seepage $\&$ prevent deformation under pressure of flask closure due to had putty index. Putty index was prepared by taking proper measurements \& that will give even thickness to resin and prevent deformation under pressure of flask closure. Additional verification of adequate acrylic resin thickness may be achieved at the packing stage using a periodontal probe, silicone putty index was used because it is stable and it will not stick to acrylic resin during trial closure. There were not previous studies shows the use of abgel with acrylic resin but there were no reaction between abgel gelatin sponge and acrylic resin. But in this study trial was done to check reaction between acrylic resin and abgel sponge spacer but there were no reaction present. Abgel gelatin sponge is used because of the properties like negligible weight, economical easily adapted to the any space \& commercially available in the market and the fact that it does not adhere to acrylic resin.

The technique has advantages over previous technique. Abgel being a lightweight\& Gamma 
sterilized sponge can be left in the denture due to its biocompatibility. Other advantages of Abgel (Gelatin sponge) spacer is that it may with stand high temperature. Finally the was prepared light. The difference between the weight of conventional denture and lightweight denture prepared by using abgel was 0.010 Grams.

\section{Summery}

In this article a technique of making light weight denture was described. In this technique putty index was used which provides even space for abgel spacer \& even resin thickness. At minimum cost.

\section{References}

1. Ohkubo C, Hosoi T. Effect of weight change of mandibular complete dentures on chewing and stability: A pilot study. J prosthetic dent. 1999;82(6):636-42.

2. ELMahdy AS.Processing a hollow obdurate. J Prosthet Dent. 1969;22:682-86.

3. Brown KE. Fabrication of a hollow-bulb obturator. $J$ Prosthet Dent. 1969;21:97-103.

4. Chalian VA, Drane JB, Standish SM. Intraoral prosthetics. In: Chalian VA, Drane JB, Standish SM, editors. Maxillofacial prosthetics: multidisciplinary practice. Baltimore: Williams \& Wilkins. 1971;133-57.

5. Fattore LD, Fine L, Edmonds DC. The hollow denture: an alternative treatment for atrophic maxillae. J Prosthet Dent. 1988;59:514-16.

6. Gardner LK, Parr GR, Rahn AO. Simplified technique for the fabrication of a hollow obturator prosthesis using vinyl polysiloxane. J Prosthet Dent. 1991;66:60-62.

7. Mc Andrew KS, Rothenberger S, Minsley GE. An innovative investment method for the fabrication of closed hollow obturator prosthesis. J Prosthet Dent. 1998;80:129-32.
8. Nidiffer TJ, Shipman TH.Hollow bulb obturator for acquired palatal openings. J Prosthet Dent. 1957;7:12634

9. Worley JL, Kniejski ME. A method for controlling the thickness of hollow obturator prostheses. J Prosthet Dent. 1983;50:227-29.

10. Ackerman AJ. Prosthetic management of oral and facial defects following cancer surgery. $J$ Prosthet Dent. 1955;5:413-32.

11. Jacobson TE, Krol AJ. A contemporary review of the factors involved in complete denture retention, stability, and support. Part I: retention. J Prosthet Dent. 1983;49:515.

12. Wormley JH, Brunton DA.Weighted mandibular dentures. J Prosthet Dent. 1974; 32:101-2.

13. Rahn AO, Boucher LJ. Maxillofacial prosthetics: principles and concepts. St. Louis: Elsevier. 1970;95.

14. Buckner H. Construction of a denture with hollow obturator, lid, and soft acrylic lining. J Prosthet Dent. 1974;31:95-99.

15. Browning JD, Kinderknecht J. Fabrication of a hollow obturator with fluid resin. J Prosthet Dent. 1984;52:89195.

16. Holt RA Jr. A hollow complete lower denture. J Prosthet Dent. 1981;45:452-54.

17. 17.Jhanji A, Stevens ST. Fabrication of one-piece hollow obturators. J Prosthet Dent. 1991;66:136-38.

18. Elliott DJ. The hollow bulb obturator: its fabrication using one denture flask. Quintessence Dent Technol. 1983;7:13-4.

19. DaBreo EL. Light-cured interim obturator prosthesis. A clinical report. J Proshet Dent. 1990;63:371-73.

How to cite the article: Dhakne V, Jadhav $P$, Limaye M, Modgi C, Patil P. Abgel a way to make light weight maxillary complete denture: An innovative technique. Ann Prosthodont Restor Dent 2018;4(4):119-121. 